\title{
MFR (Multi-purpose Field Robot) based on Human-robot Cooperative Manipulation for Handling Building Materials
}

\author{
Seungyeol Lee \\ Technical University Munich \\ Germany
}

\section{Introduction}

A field robot is defined as one that executes tasks while moving around in a dynamic environment where structures, operators and equipments are constantly changing. The basic elements of a field robot consist of a mobile platform for executing a particular operation in a dynamic environment, sensors and intelligence technology to recognize and cope with barriers in the routes in which they move, and a manipulator for executing a desired operation in place of a human (Lee et al., 1997; Wong \& Spetsakis, 2000). Field robots have been designed specifically for a particular environment and used in various industries such as agriculture, construction, engineering, space exploration and deep sea diving, due to the inherent dangers and costs associated with these fields (Hollingum, 1999; Kangari, 1991; LeMaster et al., 2003; Whitcomb, 2000).

To date, the development of field robots has focused on the basic elements, plan for a specific work or a single task. This planning leads to not only the inefficient use of time and resources but also to limited utility. To solve this problem, this paper suggests a 'MFR (Multi-purpose Field Robot)' as shown in Fig. 1. At the end of the 70's, Shimizu Co. developed 'MTV (Multi-purpose Travelling Vehicle for concrete slabs)' which could transport and guide various robotic working modules. From the viewpoint of operational characteristics, the MTV can be thought of as a construction robot designed to perform automatic grinding and cleaning of concrete surfaces. On the contrary, the MFR can be considered as a field robot designed specifically for a particular environment and used in various industries such as agriculture, construction, engineering, space exploration and deep sea diving, due to the inherent dangers and costs associated with these fields (Han, 2005).

A MFR can best be conceived in two parts: a 'basic system' consisting of a manipulator and a mobile platform, and an 'additional module' which includes sensor and intelligence technology to execute particular operations in various areas such as construction, national defense and rescue by changing this additional module. Also, continuous system maintenance and improvement is simplified due to the modularization. In this paper, the 
development of constituent technology for MFR will be discussed to realize the robotization of building materials handling at construction sites.

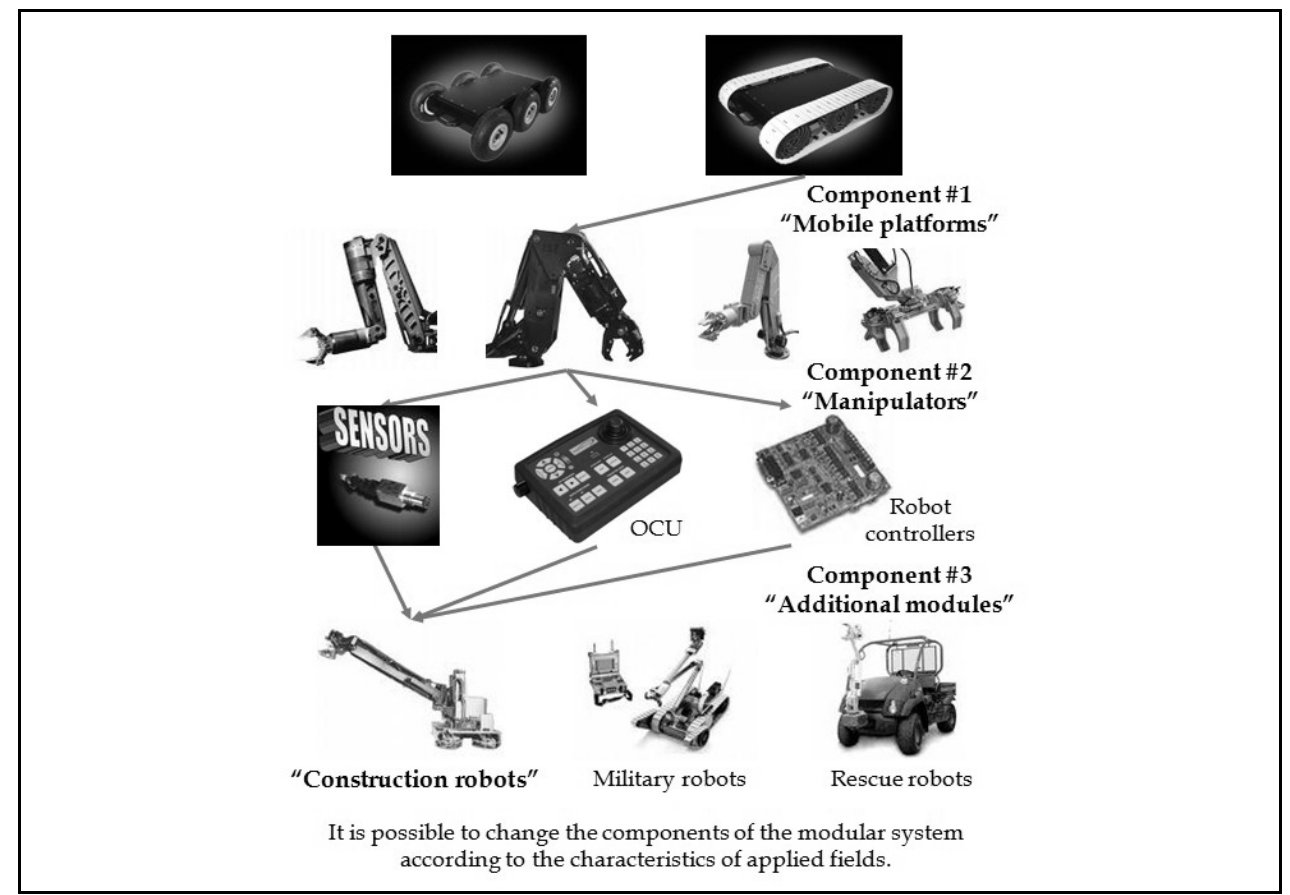

Fig. 1. Framework of MFR (Multi-purpose Field Robot)

Recent research has found that a lack of skilled manpower in the construction industry is rapidly becoming a serious problem. For example, it is estimated that there will be a shortage of about 423,000 skilled laborers by 2010 in case of Korea. This problem of a shrinking workforce, coupled with an aging society, leads to higher wages, a drop in construction quality, project delays, increased costs and the increased likelihood of accidents occurring at construction sites. One of the solutions suggested to solve these problems is robotization and automation in construction. The issue of applying 'Automation System and Robotics in Construction' has been raises as a result of the need for improvement in the safety, productivity, quality and working environment (Roozbeh, 1985; Warszawski, 1985; Albus, 1986; bernold, 1987; Skibniewski, 1988; Wen et al., 1991; Cusack, 1994; Poppy, 1994, Kochan, 2000). Sequentially, operation with automation systems and robots are widely employed at construction sites (Isao et al., 1996; Gambao et al., 2000; Choi et al., 2005; Skibniewski, 1989; Santos et al., 2003; Skibniewski \& Wooldridge, 1992; Masatoshi et al., 1996). Generally, almost half of construction work is said to be material handling. Materials and equipment used for construction are heavy and bulky for humans. Handling heavy materials has been, for the most part, eliminated for outside work by cranes and other various lifting equipment. Such equipment, however, is not available for precise work. To address curtain-walls handling needs for precise work, especially, 'ASCI (Automation 
System for Curtain-wall Installation)' has been successfully developed and applied as shown in Fig. 2.

Through the case studies on constructions, to which ASCI was applied, however, we could find some factors to be improved. Unlike the automation lines of the general manufacturing industry, construction sites rarely shows repeated operational patterns use to its unstructured processes. That is, construction robots are defined as field robots that execute tasks while operating in a dynamic environment where structures, operators, and equipment are constantly changing. To date, a guidance or remote-controlled system is the natural way to implement construction robot manipulators. However, a remote-controlled system has to solve some problems according to upper working conditions. Firstly, it is difficult to cope with malfunctions immediately when unexpected situation is occurred during construction works. Secondly, there is difficult to gain environmental information for operator's suitable commands.

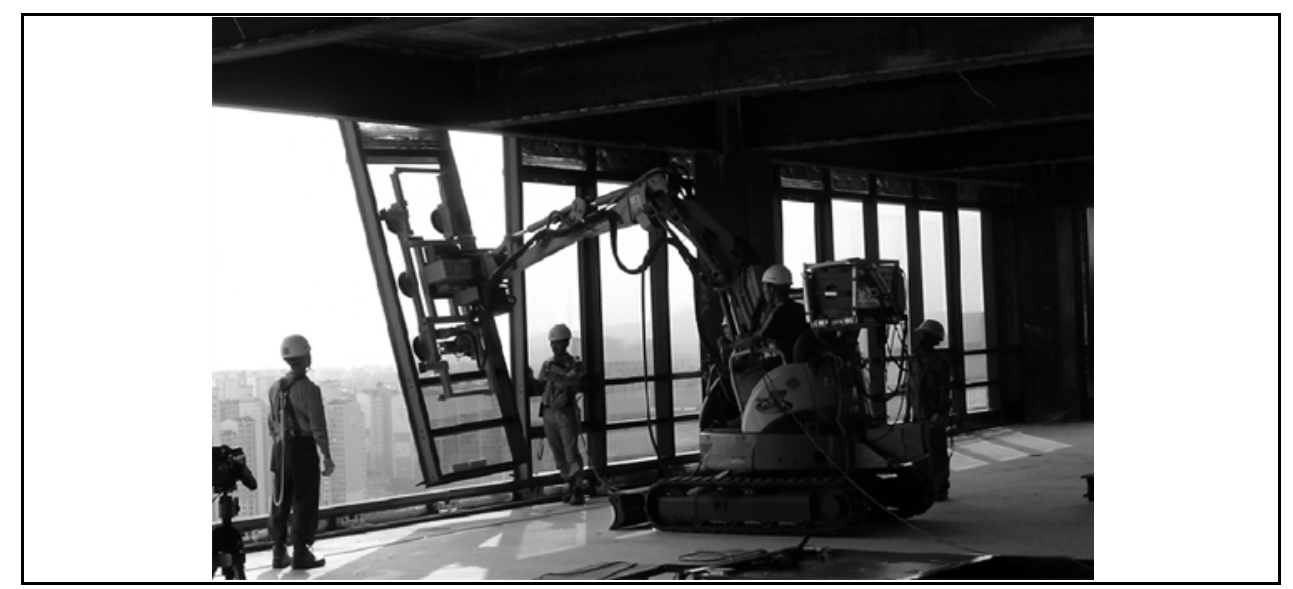

Fig. 2. An ASCI (Automation System for Curtain-wall Installation)

One of the solutions to address these problems is the technology of 'Human-Robot Cooperative Manipulation (Fukuda et. al., 1991 a; Fukuda et. al., 1991 b)' as shown in Fig. 3. Studies on the human-robot cooperation have been ceaselessly performed so far. In 1960s, the Department of Defense developed the 'Suit of Armor', which enhanced the capability of soldiers in carrying heavy materials (Miller, 1968). In 1962, the Cornell Aeronautical Lab. conducted a study on the 'Master-Slave System', which allowed a man to walk with heavy materials (Miller, 1968). The study on the Master-Slave System led up to the 'Hardiman' of GE that existed from 1966 to 1971 (Mosher, 1967). Afterward, Kazerooni suggested the 'Extender' that, unlike the Master-Slave System, delivered the operational force and information to a robot at the same time by the contact force (Kazerooni, 1989 a; Kazerooni, 1989 b; Kazerooni \& Mahoney, 1991). The Extender presented unique features of modeling through using each impedance of the three factors: human arm, extender and environment, and the controller for the operator's force and robot's force. Kosuge suggested a control algorithm for the man-robot cooperation, using maneuverability and amplification factor (Kosuge, 1993). To implement the human-robot cooperation in restricted environments, the 
impedance control method, which was proposed by Hogan, has been used as a basic force control method (Hogan, 1985).

To implement this technology, the additional module of MFR that will be combined to the basic system will be explained in two parts, first the hardware and then software. The HRI (Human-Robot Interface) device will be introduced to realize to human-robot cooperative manipulation in the hardware part. We also design a robot control algorithm, for handling building materials in cooperation between an operator and a robot. Especially, considerations on interactions among operator, robot and environment are applied to design of the robot controller. We examined the influences, which the parameters of the impedance model gave to performance of the cooperation system, through an experimental system. An installation method for the specified building material appropriate to the developed system is also suggested and a mock installation is carried out.

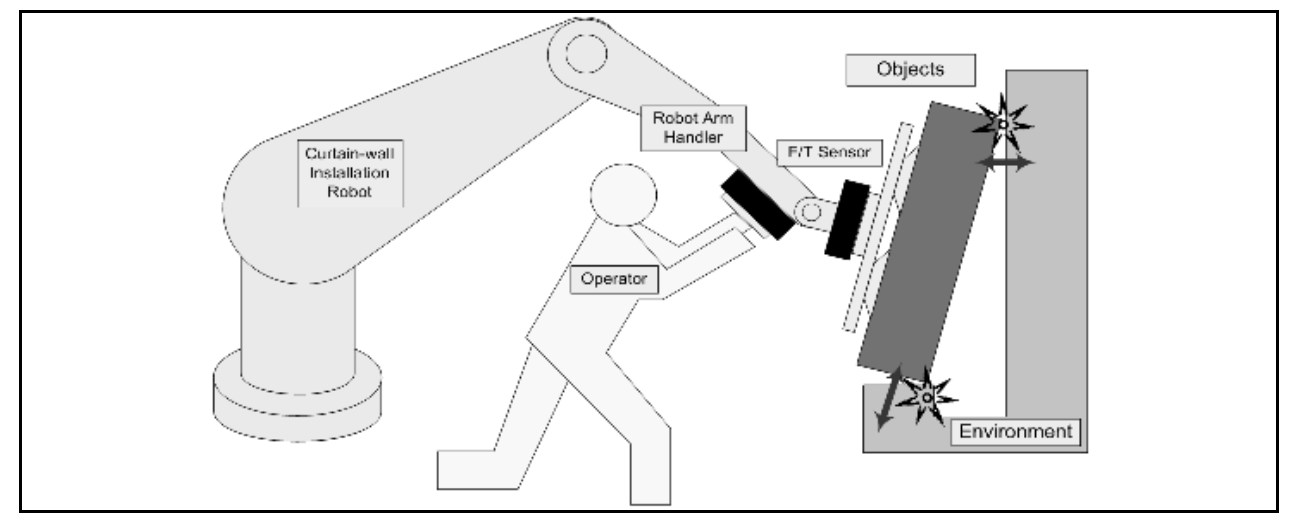

Fig. 3. Concept of human-robot cooperative manipulation

\section{Modelling of human-robot cooperative system}

Building materials handling works can be divided into 'the environment-contacting cases' and 'non-environment-contacting cases'. During contact with an environment, it acts as a dynamic constraint and affects an operator. These constraining conditions are usually avoidable through controlling actions, but some of phenomena can be considered as 'the virtual dynamic behaviors' against external forces from the environments including the operator. The mechanical relationship, between an external force and the motion toward the external force, is defined as 'the impedance', and the desired dynamic behavior of virtual system is defined as 'the target dynamics'. The operational force is measured by 'the operational force sensor' that is mounted on the last link of a manipulator, and the contact force from an environment is measured by 'the experimental force sensor' that is located between the last link and the end effector. While the case, an operator handles a building material on an obstacle-free place, is defined as 'the unconstrained condition', the case, an operator performs work under interactions with environments, is defined as the operation in 'the constrained condition'. 


\subsection{Unconstrained condition}

In Fig. 4, the force(torque), measured by the operational force sensor which is generated by the operator, is $F_{h}\left(T_{h}\right)$, and the impedance parameters, that are related to a desired dynamic behavior, are $M_{p t}\left(M_{o t}\right)$ and $B_{p t}\left(B_{o t}\right)(n \times n$ positive definite diagonal inertia and damping matrices) respectively. Here, the desired dynamic behavior of a robot can be given, with the input $F_{h}\left(T_{h}\right)$, by an impedance equation (1). The subscript ' $\mathrm{p}$ ' stands for the position and 'o' stands for the orientation, and $\lambda$ means the power assist ratio of an operator.

The $K$ (stiffness matrices) parameter, having the property of a spring, was excluded as it disturbed the operation to move a building material to a desired position with the operational force. Ultimately, adjusting each of the impedance parameters equals to adjusting the dynamic behavior of a virtual system. The dynamic behavior, generated from the impedance equation (1) when an operator applies force to a virtual system, is used as a reference that a robot system should follow to move a building material.

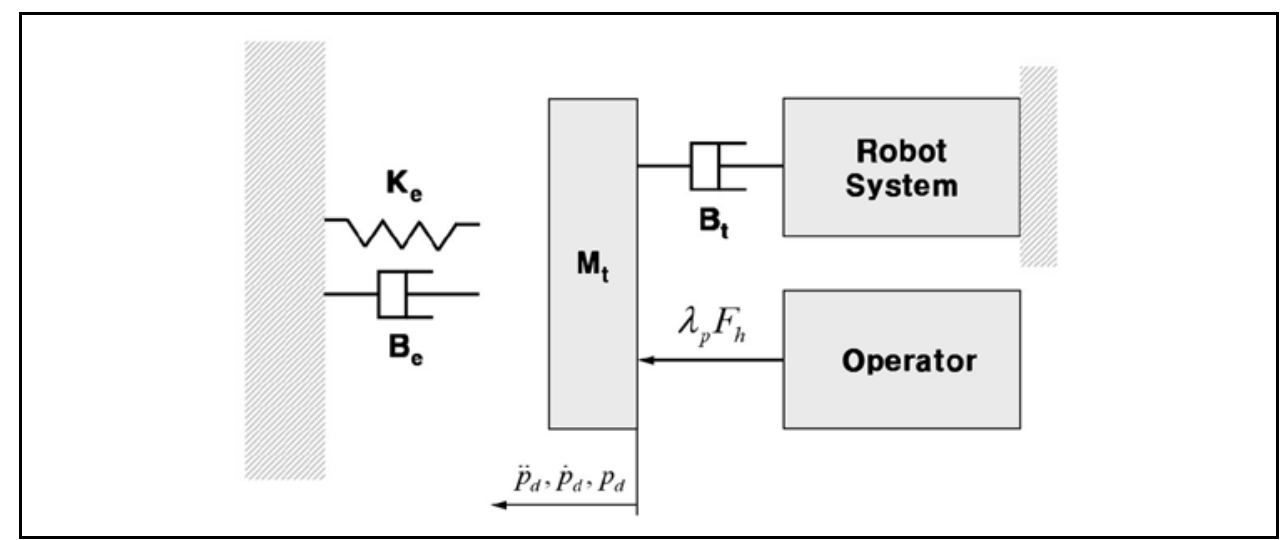

Fig. 4. Modelling of unconstrained condition

$$
\begin{aligned}
& M_{p t} \ddot{p}_{d}+B_{p t} \dot{p}_{d}=\lambda_{p} F_{h} \\
& M_{o t} \ddot{\varphi}_{d}+B_{o t} \dot{\varphi}_{d}=\lambda_{o} T^{T}\left(\varphi_{d}\right) T_{h} \\
& \text { where, } \varphi=\left[\begin{array}{lll}
\alpha & \beta & \gamma
\end{array}\right]^{T} \\
& T=\left[\begin{array}{ccc}
0 & -s \alpha & c \alpha s \beta \\
0 & c \alpha & s \alpha s \beta \\
1 & 0 & c \beta
\end{array}\right]
\end{aligned}
$$

\subsection{Constrained condition}

In Fig. 5, the force (torque) that was measured by the operational force sensor is $F_{h}\left(T_{h}\right)$, and the force (torque) that was measured by the experimental force sensor is $F_{e}\left(T_{e}\right)$. With the input values of $F_{h}\left(T_{h}\right)$ and $F_{e}\left(T_{e}\right)$, unlike an operation in the unconstrained condition, the desired dynamic behavior of a robot can be described by an impedance equation (2). For the 
same reason with case of the unconstrained condition, the $K$ (stiffness matrices), having the property of a spring, was excluded.

In case interactions with an environment occur (a constraint condition), the end effector should endow with a behavior, considering the compliance. In this regard, we defined the relationship between the contact force (torque) and the dynamic behavior (position, velocity and acceleration) error of the end effector, through the generalized active impedance, as in (3). Thus, the end effector can have linear and dependant impedance characteristics to the translation part, for which the contact force $F_{e}$ was considered, and the rotation part, for which the equivalent contact moment $T^{T} T_{e}$ was considered. In the (3), $M_{p e}\left(M_{o e}\right), B_{p e}\left(B_{o e}\right)$, $K_{p e}\left(K_{o e}\right)$ are the environmental impedance parameters that determine a dynamic behavior of the end effector for interactions with an environment.

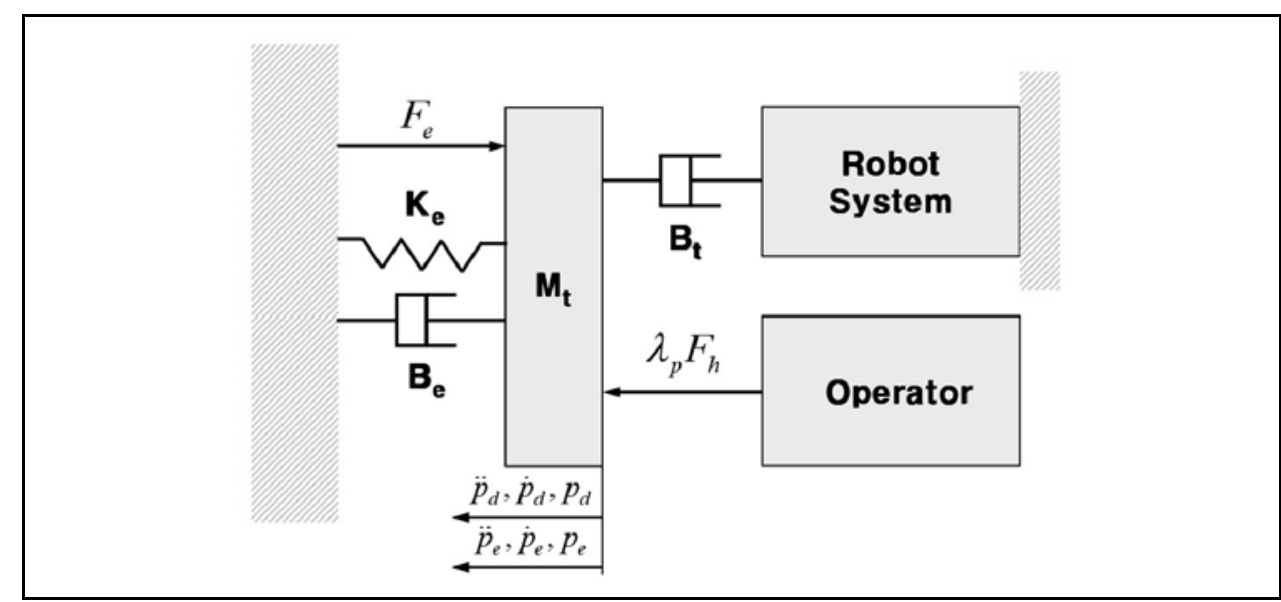

Fig. 5. Modelling of constrained condition

$$
\begin{aligned}
& M_{p t} \ddot{p}_{d}+B_{p t} \dot{p}_{d}=\lambda_{p} F_{h}-F_{e} \\
& M_{o t} \ddot{\varphi}_{d}+B_{o t} \dot{\varphi}_{d}=T^{T}\left(\varphi_{d}\right)\left(\lambda_{o} T_{h}-T_{e}\right) \\
& M_{p e} \Delta \ddot{p}_{d e}+B_{p e} \Delta \dot{p}_{d e}+K_{p e} \Delta p_{d e}=F_{e} \\
& M_{o e} \Delta \ddot{\varphi}_{d e}+B_{o e} \Delta \dot{\varphi}_{d e}+K_{o e} \Delta \varphi_{d e}=T^{T}\left(\varphi_{e}\right) T_{e} \\
& \text { where, } \Delta p_{d e}=p_{d}-p_{e}
\end{aligned}
$$

The dynamic behavior is determined, as shown in (3), by the environmental contact force and impedance characteristics. The dynamic behavior error indicates the difference between the desired dynamic behavior and the actual dynamic behavior of the end effector. That is to say, it explains that a robot system cannot practically follow a desired dynamic behavior, but indicates a level of compliance with an environment. 


\section{Control strategy of human-robot cooperative manipulation}

\subsection{Adjustment of impedance parameters}

We categorized the building materials handling work through the human-robot cooperative manipulation into the environment-contacting case and the non-environment-contacting case. From the viewpoint of operational characteristics, the former case can be thought as 'the press fit operation' under interactions with other building materials or obstacles, which requires relatively higher stability. On the contrary, the latter case can be considered as the operation of moving building materials promptly to an installation site, which requires relatively higher mobility. In a human-robot cooperative system, we can make the virtual system have specific impedance characteristics through the modeling of human-robot cooperative system. To get the high stability, the virtual system may have a damping characteristic. However, too much damping decreases the mobility of the system. In this strategy, the impedance parameters of the virtual system are adjusted corresponding to the operational characteristics of the building materials handling work.

In the impedance equation (2), the impedance parameters $M_{p t}\left(M_{o t}\right)$ and $B_{p t}\left(B_{o t}\right)$ are switched to proper values when an operator requires stability or mobility according to the operational characteristics of the work process. The appropriate parameter values are determined through enough simulations with an experimental system. Also, each of the impedance parameters should be adjusted by stage according to the choice of an operator. This adjusting way is also applied exactly to adjustment of the power assist ratio $(\lambda)$ of an operator.

\subsection{Inner motion control loop}

The selection of suitable impedance parameters that guarantee a satisfactory compliant behavior during the interaction may turn out to be inadequate to ensure accurate tracking of the desired position and orientation trajectory when the robot moves in unconstraint condition. A solution to this drawback can be devised by separating the motion control action from the impedance control action as follows. The motion control action is purposefully made stiffness so as enhance disturbance rejection but, rather than ensuring tracking of a reference position and orientation, it shall ensure tracking of a reference position and orientation resulting from the impedance control action. In other words, the desired position and orientation together with the measured contact force and moment are input to the impedance equation which, via a suitable integration, generates the position and orientation to be used as a reference for the motion control action.

In order to realize the above solution, it is worth introducing a reference frame other than the desired frame specified by a desired position vector $p_{d}$ and a desired rotation matrix $R_{d}$. This frame is referred to as the compliant frame, and is specified by a position vector $p_{c}$ and a rotation matrix $R_{c}$. In this way, the inverse dynamics motion control strategy can be still adopted as long as the actual end effector position $p_{e}$ and orientation $R_{e}$ is taken to coincide with $p_{c}$ and $R_{c}$ in lieu of $p_{d}$ and $R_{d}$, respectively. Accordingly, the actual end effector linear velocity $\dot{p}_{e}$ and angular velocity $\omega_{e}$ are taken to coincide with $\dot{p}_{c}$ and $\omega_{c}$, respectively. 
A block diagram of the resulting scheme is sketched in Figure 16 and reveals the presence of an inner motion control loop with respect to the outer impedance control loop. In view (2), the impedance equation is chosen so as to enforce an equivalent mass-damper-spring behavior for the position displacement when the end effector exerts a force (torque) $F_{e}\left(T_{e}\right)$ on the environment, i.e.

$$
\begin{aligned}
& M_{p e} \Delta \ddot{p}_{d c}+B_{p e} \Delta \dot{p}_{d c}+K_{p e} \Delta p_{d c}=F_{e} \\
& M_{o e} \Delta \ddot{\varphi}_{d c}+B_{o e} \Delta \dot{\varphi}_{d c}+K_{o e} \Delta \varphi_{d c}=T^{T}\left(\varphi_{e}\right) T_{e} \\
& \text { where, } \Delta p_{d c}=p_{d}-p_{c}
\end{aligned}
$$

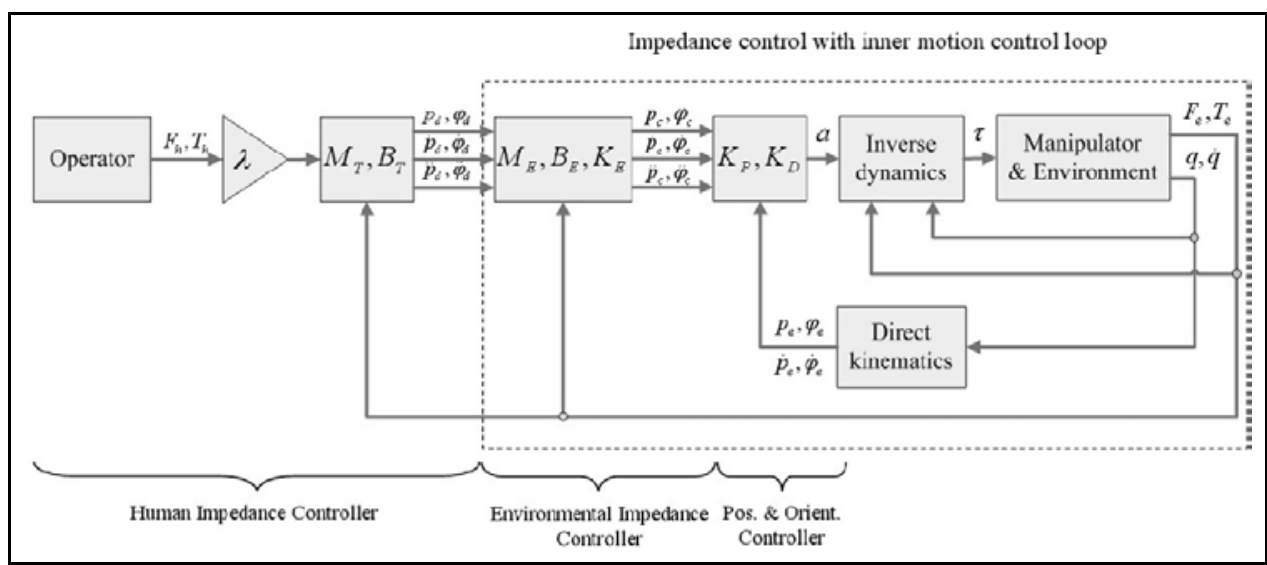

Fig. 6. Block diagram for human-robot cooperative manipulation

With reference to the scheme in Fig. 6, the impedance control generates the reference position for the inner motion control. Therefore, in order to allow the implementation of the complete control scheme, the acceleration shall be designed to track the position and the velocity of the compliant frame, i.e.

$$
\begin{aligned}
& a_{p}=\ddot{p}_{c}+K_{D p} \Delta \dot{p}_{c e}+K_{P p} \Delta p_{c e} \\
& a_{o}=T\left(\varphi_{e}\right)\left(\ddot{\varphi}_{c e}+K_{D o} \Delta \dot{\varphi}_{c e}+K_{P o} \Delta \varphi_{c e}\right)+\dot{T}\left(\varphi_{e}, \dot{\varphi}_{e}\right) \dot{\varphi}_{e} \\
& \text { where, } \Delta p_{c e}=p_{c}-p_{e}
\end{aligned}
$$

Notice that $p_{c}$ and its associated derivatives can be computed by forward integration of the impedance equation (4) with input $F_{e}\left(T_{e}\right)$ available from the force/torque sensor.

\subsection{Experiments and results}

As shown in Fig. 7, we mounted two sensors in the 2DOF manipulator, moving in the $\mathrm{x}$ and $y$ axes. One receives operational signals from an operator, and the other, positioned between 
the end effector and the $15 \mathrm{~kg}$ weighing object, can detect the contact force from the environment. With the signals that are received by the two sensors, the control signals, the manipulator should follow, are generated from the robot controller. The manipulator is controlled using an impedance control with inner motion loop method based on the robot force control. It assumes that the manipulator follows a commanded force derived by equation (6) (a Lagrange formulation). The sampling time for the force analysis and controlling the manipulator is settled as $1 \mathrm{msec}$. A mount string was used for the environmental system. The stiffness for an actual environment can be adjusted through replacement of the spring.

The experimental methods for the human-robot cooperation-work can be categorized into four staged.

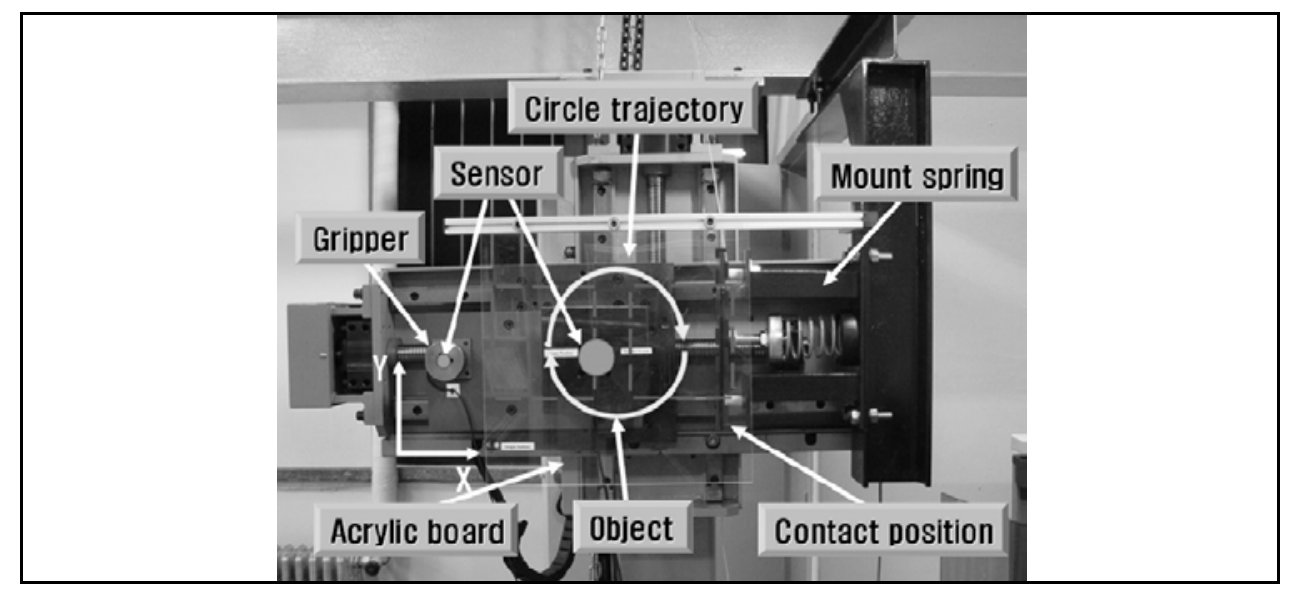

Fig. 7. Experimental system (2-DOF manipulator)

$$
\left[\begin{array}{l}
F_{1} \\
F_{2}
\end{array}\right]=\left[\begin{array}{cc}
m_{1}+m_{2} & 0 \\
0 & m_{2}
\end{array}\right]\left[\begin{array}{l}
\ddot{d}_{1} \\
\ddot{d}_{2}
\end{array}\right]+\left[\begin{array}{c}
m_{1} g+m_{2} g \\
0
\end{array}\right]+\left[\begin{array}{l}
F_{e y} \\
F_{e z}
\end{array}\right]
$$

1) An indicator (a needle), mounted on an object, automatically moves to the start position.

2) The operator applies force to the gripper (HRI device), so that the indicator follows a circle trajectory that is described on an acrylic board.

3) Based on the operational force, the robot follows the circle trajectory through the impedance control in the unconstraint condition.

4) The robot contacts a mount spring (environmental system) while following the circle trajectory. The contact force, generated at this time, enables the impedance control, and the robot finishes a building material handling work in compliance with an environment.

The experimental contents are as follows; Firstly, the influences of each parameter are to be observed for adjustment of the impedance parameters. Secondly, the performance of the 
suggested impedance control with inner motion control loop is to be evaluated to reduce the position following error for operation of a robot in an unconstrained condition. Thirdly, the influences of $F_{h}$ and $F_{e}$, according to change of the power assist ratio $(\lambda)$ of an operator, are to be studied. Finally, the changes of $F_{h}$ and $F_{e}$, according to the changes of the actual environmental stiffness, are to be investigated (Lee et al., 2007).

\subsubsection{Influence of impedance parameters}

The factors are given as the impedance parameters $M_{p t}\left(M_{o t}\right)$ and $B_{p t}\left(B_{o t}\right)$ in (2), and the levels are given as 1,3 , and 10 . The force, used for the two experiments, is $5 \mathrm{~N}$ and applied for around $10 \mathrm{sec}$. The $K$ value is to be set to $1 \mathrm{~N} / \mathrm{m}$ for convergence of graphs. As a result of experiments, $M_{p t}\left(M_{o t}\right)$ is related to an operation that requires mobility in building materials handling processes. That is to say, this operation does not require relatively higher stability, but requires prompt movement of an object to a desired position with small operational force. As the $M_{p t}\left(M_{o t}\right)$ value rises, an object can be moved to a long-distance place with big operational force. However, $B_{p t}$ is related to an operation that requires stability in building materials handling processes. That is to say, this case does not require relatively higher mobility, but requires a precise and stable operation. As $B_{p t}\left(B_{o t}\right)$ value rises, the distance of movement by the same operational force gets shorter. As the mobility is reduced, the more demanding force may make an operator feel the minimum moving distance shorter.

\subsubsection{Influence of inner motion control loop}

Without the operational force, the constant force, which is input to the controller, makes the robot follow an already-programmed circle trajectory. It can be recognized that the path tracking accuracy is rather poor during execution of the whole tasks if the stiffness parameter is small. The small stiffness parameter also causes reduction of the contact force in the constraint condition. These results occur due to a larger end effector position error in operation. To solve these problems, we proposed the impedance control with an inner motion control loop. The inner motion loop gains in (5) have been set as $K_{D p}=1.5 I$ and $K_{P p}=15 I$. According to the experiment, the robot operation without the inner motion control loop shows inferior desired-position-following performance in an unconstraint condition. By using the inner motion control loop, the high following performance can be obtained.

\subsubsection{Influence of power assist ratio}

The power assist ratio $(\lambda)$, suggested in (1) and (2), plays a role of controlling the scale of the force that is required by an operator for a human-robot cooperative manipulation. In the experiments, we studied changes of $F_{h}$ and $F_{e}$ when the power assist ratio $(\lambda)$ was increased from 3 to 6 . As $\lambda$ increased to 6 from $3, F_{h}$, required in case of no contact with the environment, was reduced by a half, and $F_{h}$ for the environment-contacting case was also reduced by around a half. We can see that the force, required by an operator, gets smaller as $\lambda$ increases, but there is no significant change in the force $\left(F_{e}\right)$ that reflects in the contacting condition. 


\subsubsection{Influence of environmental stiffness parameter}

The environmental stiffness $\left(K_{e}\right)$ depends on the characteristics of materials, composing an environment. The purpose of this experiment, changing the environmental stiffness, lies on comparison of the contact force $\left(F_{e}\right)$ that is felt by an operator according to operational conditions such as a case contact with an obstacle occurs or a case the press fit is required. It can be recognized that, as $K_{p e}$ increases, the force, required by an operator, gets increased and the force $\left(F_{e}\right)$, reflecting in the contact condition, gets increased, too.

\section{The basic system of a MFR (Multi-purpose Field Robot) for handling building materials}

The MFR system combines a basic system with an additional module for construction. Considering workspace and mobility, a 6DOF (degree-of-freedom) manipulator and a 3DOF mobile platform were suggested for use in the basic system. Moreover, it was possible to change the components of the basic system according to load specifications.

\subsection{A multi (6)-DOF manipulator}

Fig. 8 shows the 6 DOF manipulator of a basic system. This robot is a special case manipulator where the centers of the last 3 axes meet in the center of the robot wrist. The kinematic analysis in such form of manipulator can be divided into 2 link chains (the first 3 link chains and then the other 3 link chains). Table 1 shows the specifications of the manipulator.

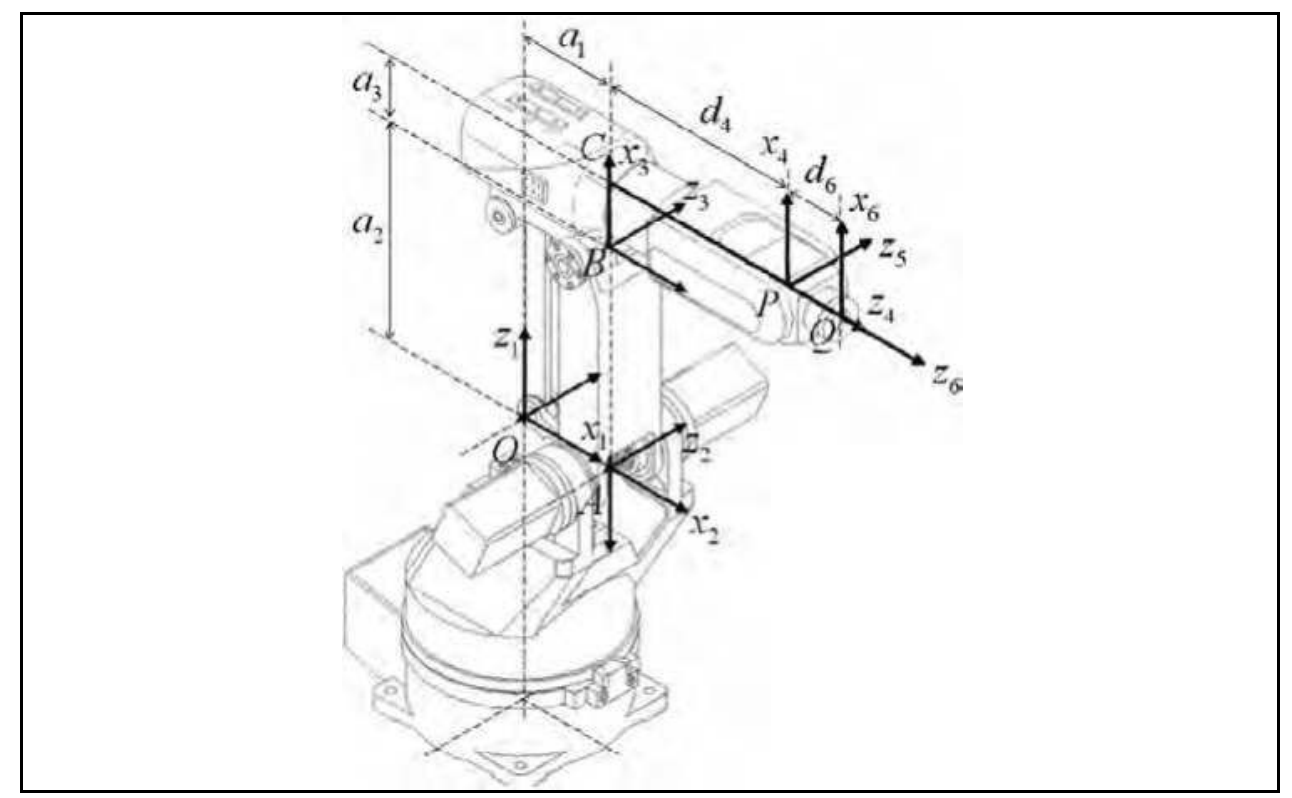

Fig. 8. A 6DOF manipulator (Samsung Electronics Co. ltd) 


\begin{tabular}{|c|c|c|}
\hline \multicolumn{2}{|c|}{ specification } & value \\
\hline \multicolumn{2}{|c|}{ Degree of Freedom } & 6 \\
\hline \multicolumn{2}{|c|}{ Weight Capacity } & $58.38(N)$ \\
\hline \multicolumn{2}{|c|}{ Arm Length(max) } & $858(\mathrm{~mm})$ \\
\hline \multicolumn{2}{|c|}{ Velocity of End-effector } & $30(\% \mathrm{sec})$ \\
\hline \multirow{2}{*}{ Weight } & Manipulator & $588(N)$ \\
\hline & Controller & $245(N)$ \\
\hline
\end{tabular}

Table 1. Specifications of the 6DOF manipulator

The forward kinematics of the manipulator is defined by the question of solving for the position and direction of the end-effector according to each degree of the joints. That is, it is the problem of solving the position vector and rotational matrix of the end-effector. The kinematic analysis of the manipulator can be executed with any coordinate system but the most typical one is Denavit-Hartenberg Notation (noted as D-H notation below). The unknown kinematics values of a series manipulator can be solved by multiplying the homogeneous matrix defined in the following (7) and solved similar to (8).

$$
\begin{aligned}
& H=R\left(\theta_{i}, z\right) T\left(d_{i}, z\right) T\left(a_{i}, x\right) R\left(\alpha_{i}, x\right) \\
&=\left[\begin{array}{cccc}
\cos \theta_{i} & -\sin \theta_{i} \cos \alpha_{i} & \sin \theta_{i} \sin \alpha_{i} & a_{i} \cos \alpha_{i} \\
\cos \theta_{i} & \cos \theta_{i} \cos \alpha_{i} & -\cos \theta_{i} \sin \alpha_{i} & a_{i} \sin \alpha_{i} \\
0 & \sin \alpha_{i} & \cos \alpha_{i} & d_{i} \\
0 & 0 & 0 & 1
\end{array}\right] \\
&{ }_{0}^{n} H={ }_{0}^{1} H \cdot{ }_{1}^{2} H_{i} \ldots{ }_{n-1}^{n} H_{i}=\left[\begin{array}{ccc}
{ }_{0}^{n} R & { }^{0} P_{n} \\
0 & 1
\end{array}\right] \\
&{ }_{6}^{0} H=\left[\begin{array}{cccc}
u_{x} & v_{x} & w_{x} & q_{x} \\
u_{y} & v_{y} & w_{y} & q_{y} \\
u_{z} & v_{z} & w_{z} & q_{z} \\
0 & 0 & 0 & 1
\end{array}\right]
\end{aligned}
$$

Table 2 shows the D-H parameters through the D-H notation using the coordinate system defined in Figure 8 . The position of the end-effector can be calculated by substituting a given parameter into the D-H transformation matrix in (8). 


\begin{tabular}{|c|c|c|c|c|}
\hline$i$ & $\alpha_{i}\left({ }^{\circ}\right)$ & $a_{i}(\mathrm{~mm})$ & $d_{i}(\mathrm{~mm})$ & $\theta_{i}{ }^{\left({ }^{\circ}\right)}$ \\
\hline 1 & -90 & $a_{1}$ & 0 & $\theta_{1}$ \\
\hline 2 & 0 & $a_{2}$ & 0 & $\theta_{2}$ \\
\hline 3 & -90 & $a_{3}$ & 0 & $\theta_{3}$ \\
\hline 4 & 90 & 0 & $d_{4}$ & $\theta_{4}$ \\
\hline 5 & -90 & 0 & 0 & $\theta_{5}$ \\
\hline 6 & 0 & 0 & $d_{6}$ & $\theta_{6}$ \\
\hline
\end{tabular}

Table 2. D-H parameters of the 6DOF manipulator

\subsection{A mobile platform}

A $6 \mathrm{DOF}$ manipulator was fitted to the top plate of the mobile platform. Thus, movement of the manipulator was possible according to the platform's DOF. Traveling on uneven surfaces or surfaces with barriers was made possible using caterpillar tread.

Table 3 shows the specifications of the suggested mobile platform. This mobile platform largely consisted of caterpillar tread, a top plate and a controller as shown in Fig. 9. The caterpillar tread was powered by 2 DC motors with a reduction gear. Also, perpendicular movement of the top plate was achieved through a hydraulic cylinder. Through such movement mechanisms, 3DOF movement of forward and backward $\left(\mathrm{T}_{\mathrm{y}}\right)$, left and right rotation $\left(\mathrm{R}_{\mathrm{z}}\right)$ and perpendicular movement of the top plate was realized with the central axis $(Z)$ of the mobile platform as the base. It was possible to control movement through both wired and wireless controllers and traveling speed was controlled through an internal controller.

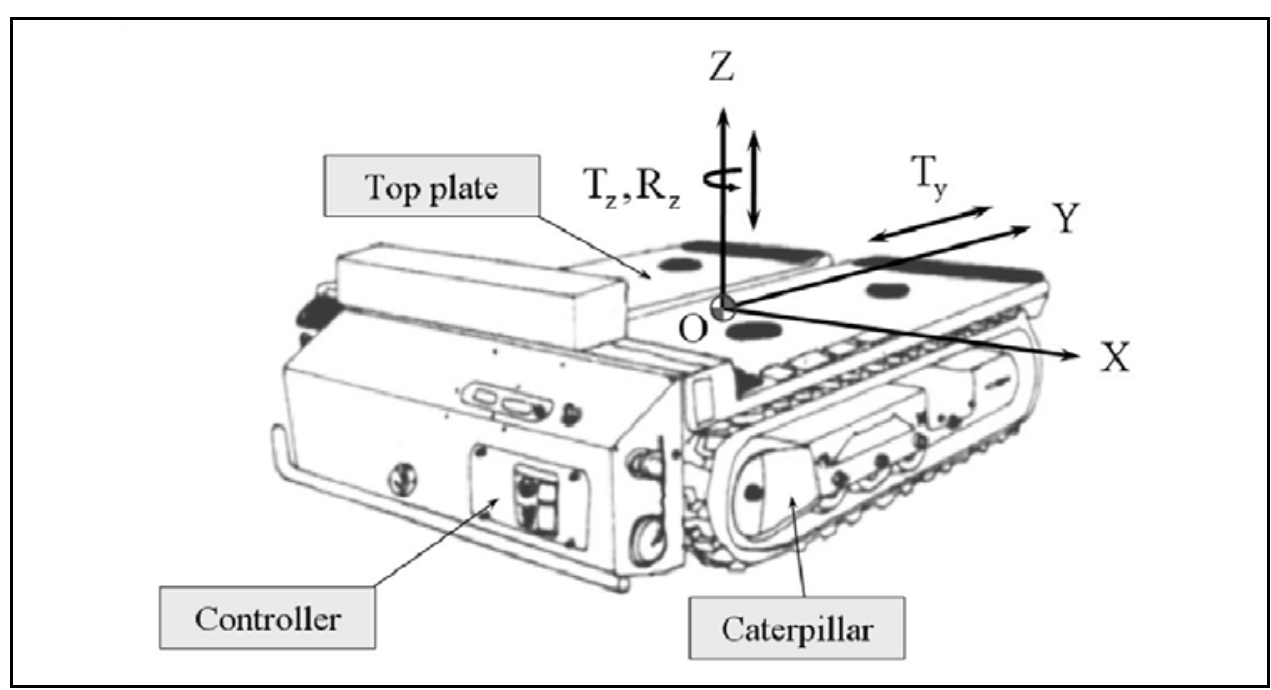

Fig. 9. A mobile platform (Kajima Mechatro Engineering Co.) 


\begin{tabular}{|c|c|c|}
\hline \multicolumn{2}{|c|}{ specification } & value \\
\hline \multicolumn{2}{|c|}{ Maximum load of carriage } & $9800(N)$ \\
\hline \multicolumn{2}{|c|}{ Weight } & $3920(N)$ \\
\hline \multicolumn{2}{|c|}{ Length } & $1,260(\mathrm{~mm})$ \\
\hline \multicolumn{2}{|c|}{ Breadth } & $900(\mathrm{~mm})$ \\
\hline \multirow{2}{*}{ Velocity } & Maximum & $2.5(\mathrm{~km} / \mathrm{h})$ \\
\hline & Minimum & $0.6(\mathrm{~km} / \mathrm{h})$ \\
\hline \multicolumn{2}{|c|}{ Inclination of degree } & $20\left(^{\circ}\right)$ \\
\hline \multicolumn{2}{|c|}{ Power consumption } & $0.8(\mathrm{~kW})$ \\
\hline \multicolumn{2}{|c|}{ Source of electricity } & Charging battery \\
\hline
\end{tabular}

Table 3. Specifications of the mobile platform

\section{The additional module of a MFR (Multi-purpose Field Robot) for handling building materials}

An additional module, which is used for construction work along with various devices, was suggested for incorporating the MFR into construction work. This module consisted of hardware (HRI: Human-Robot Interface) and software (HRC control: Human-Robot Cooperative control).

\subsection{A HRI (Human-Robot Interface)}

First, the robot controller needs to be able to implement DOF for a mobile platform and a 6DOF manipulator.

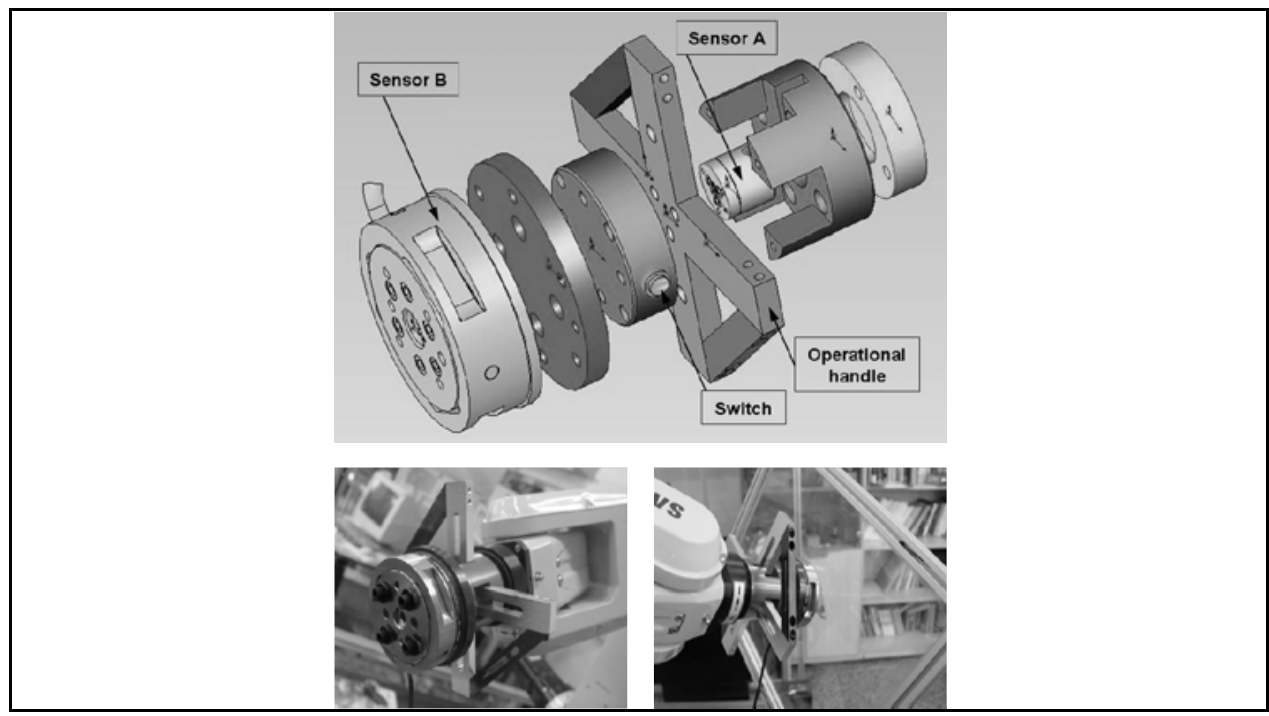

Fig. 10. The first robot controller (HRI device) 
The first robot controller (HRI device) is shown in Fig. 10. As seen in this figure, if an operator puts external force containing an operation command on a handler of the robot controller, it is converted into a control signal to operate the robot with 'sensor A (6DOF force/torque sensor; ATI Industrial Automation, Inc.)'.

Here, if the robot comes in contact with an external object, information on the contact force is transmitted to the robot controller through 'sensor B (6DOF force/torque sensor)'. It is important to note that external force transmitted through sensor B and that transmitted to sensor A should operate separately from each other. In addition, the switch attached to the HRI device should be able to control the manipulator and mobile platform separately. That is, it plays a role of determining whether external force being inputted is a control signal for the manipulator or that for the mobile platform.

In MFR system, the operator can select between two communication methods: wired or wireless control. The wireless control system is used to carry materials long distances or to move a robot to places that are difficult for an operator to reach. The wired control system is used to install construction materials by cooperation or in an emergency.

For the wireless communication system, it is then possible to choose between the mobile platform control system and the manipulator control system. In other words, it is possible to control a mobile platform and a manipulator with one wireless controller (Fig. 11(a)). Each control signal is transmitted to the controller of a manipulator and a mobile platform through a main controller via a RF communication module and a converter.

For the wired communication system, it is again possible to choose between the cooperation-based control system and the emergency control system. Unlike the wireless communication system, the wired communication system uses a separate control unit. The cooperation-based control system operates through main controllers including industrial computers and sensors, and the first robot controller (HRI device) mentioned in Paragraph 5.1. The emergency control system can operate through the teach pendant of a manipulator and a mobile platform in emergency situations, as seen in Figure 11(b).

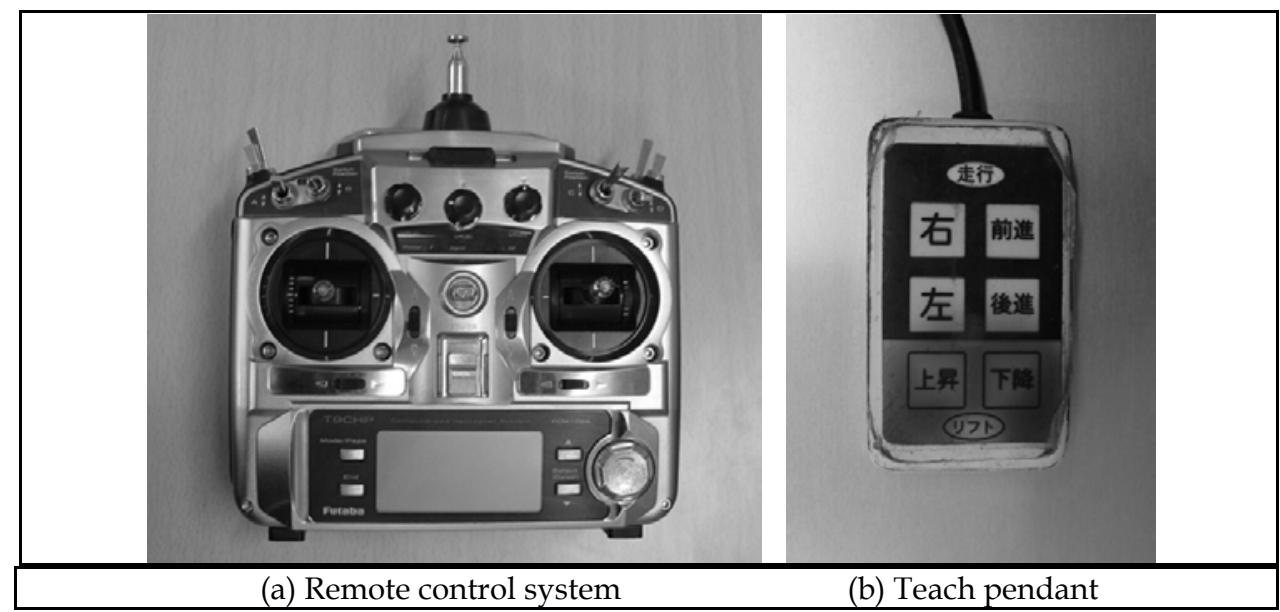

Fig. 11. The second robot controller (remote control system \& teach pendant) 


\subsection{The software of the additional module}

The software of the suggested additional module for construction works refers to a control algorithm, primarily necessary for handling building materials by human-robot cooperative manipulation. In this study, remote control, human-robot cooperation-based control, and emergency control are proposed as methods to control a MFR for handling building materials.

Fig. 12 shows an overall flow-chart for the suggested robot control methods. The operator can select between two communication methods: wired or wireless control. The wireless control system is used to carry materials long distances or to move a robot to places that are difficult for an operator to reach. The wired control system is used to handle building materials by cooperation or in an emergency. For the wireless communication system, it is then possible to choose between the mobile platform control system and the manipulator control system. In other words, it is possible to control a mobile platform and a manipulator with one wireless controller (Figure 11(a)). For the wired communication system, it is again possible to choose between the cooperation-based control system and the emergency control system. Unlike the wireless communication system, the wired communication system uses a separate control unit. The cooperation-based control system operates through main controllers including industrial computers and sensors, and the first robot controller (HRI device).

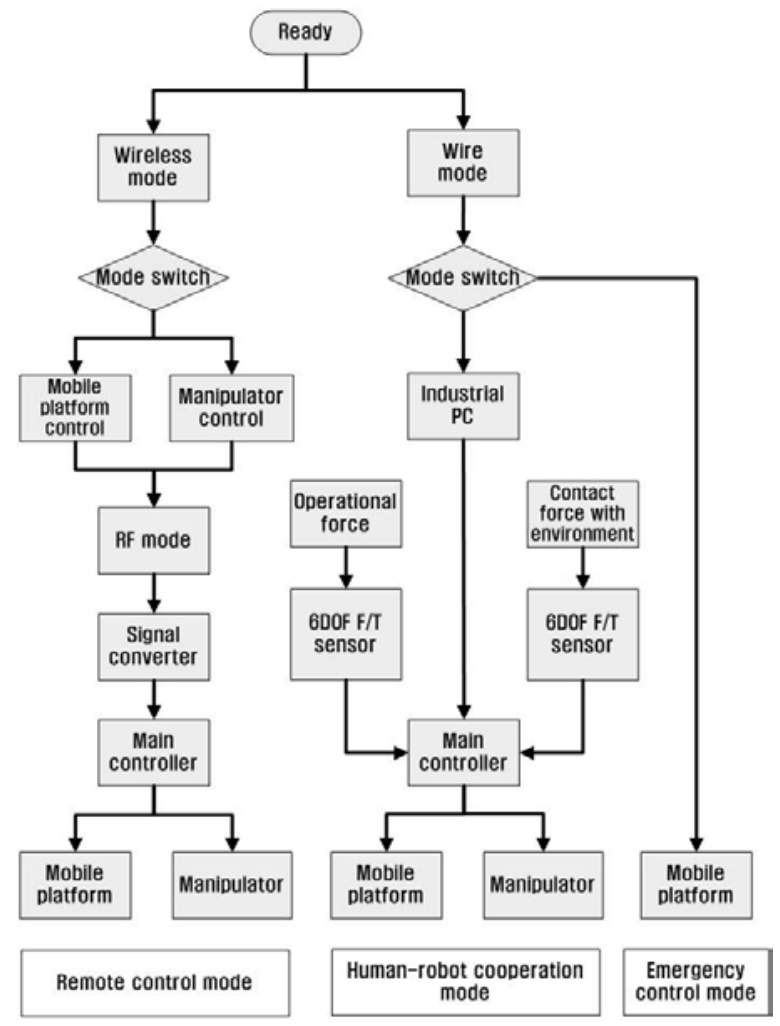

Fig. 12. Flow-chart for MFR control methods 
The emergency control system can operate through the teach pendant of a manipulator and a mobile platform in emergency situations, as seen in Figure 11(b).

Handling of building materials by the cooperation-based control system can be largely divided as below.

1) Process of transporting materials to an installation position

2) Process of inserting them into the correct position or doing press pits, depending on the environment

In previous chapter 2, the former is defined as free space movement (motion under unconstrained conditions) and the latter as motion under constrained conditions. Free space motion needs rapid movement with relatively low precision while motion under constrained conditions needs precise motion with relatively low motion velocity. According to modeling of the interactions among the operator, robot and environment, we designed an impedance controller for the human-robot cooperation (Fig. 13). When an operator judges that the position $(X)$ to which a robot carries materials fails to agree with the position $\left(X_{d}\right)$ to which he or she wants to carry them, his or her force is transmitted to sensor A. In particular, external force $\left(F_{h}\right)$ measured by sensor A can be used by operators from various age groups through the force augmentation ratio $(\alpha)$. That is, all people, regardless of muscular strength, can operate a robot by the force augmentation ratio. In terms of an operator's inputted force and the contact force $\left(F_{e}\right)$ with environments inputted from sensor $\mathrm{B}$, the target dynamics needed for operation are determined by the following equation (8) for impedance. Of the dynamics values, the deviation between the target position $\left(X_{d}\right)$ and the present position $(X)$ decreases as feedback is received through the encoder of a position/direction controller, resulting in 0 . In other words, the current deviation is inputted into a servo controller, which causes a manipulator to pursue the target position value. In addition, it is possible to adapt the operation properties of a robot's motion characteristics by controlling the impedance parameters $\left(M_{t}, B_{t}\right)$ in (9). Relatively rapid and precise motions can be implemented by controlling these parameters.

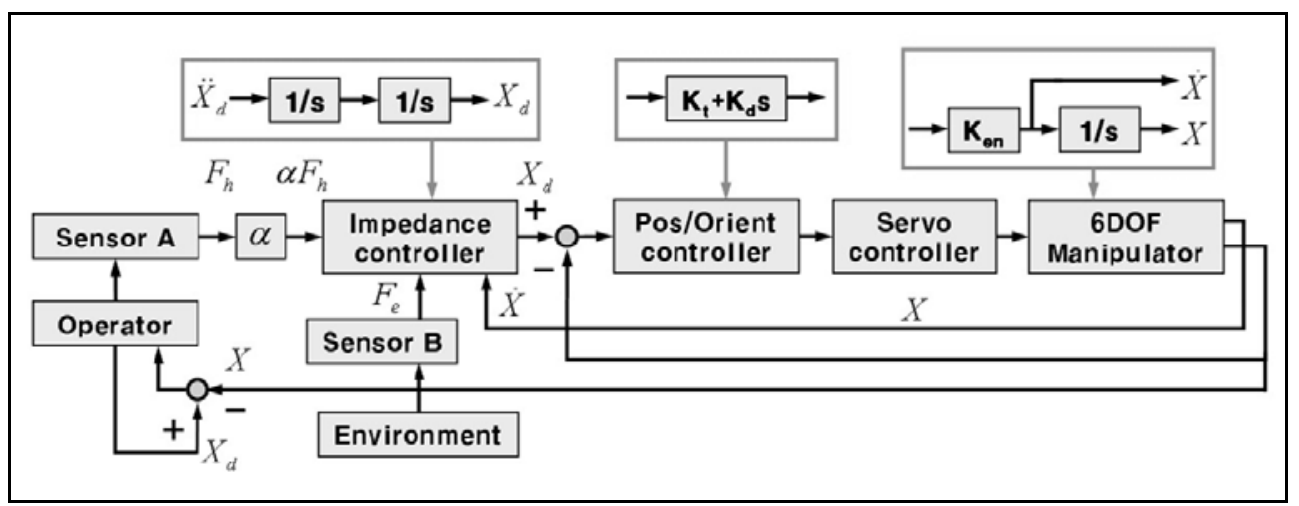

Fig. 13. Block diagram for human-robot manipulation of MFR

$$
\ddot{X}_{d}=\left(M_{t}\right)^{-1}\left\{\left(\alpha F_{h}-F_{e}\right)-B_{t} \dot{X}_{d}\right\}
$$


where, $\ddot{X}_{d}$ : Acceleration related target dynamics

$\dot{X}_{d}:$ Velocity related target dynamics

$M_{t}$ : Inertia related impedance parameter in the virtual system

$B_{t}$ : Damping related impedance parameter in the virtual system

\section{Experiment with the prototype of a MFR}

Fig. 14 shows the prototype of a MFR for handling building materials. In this figure, the basic system consists of a 6DOF manipulator and a mobile platform with caterpillar tread; the portion that excludes building material is an additional module (robot controller, vacuum suction device, F/T sensor and controller etc.) for handling building materials.

The development of a MFR applied to the construction area is not achieved by actual system production alone. Studies on system operation technology are also necessary for the developed system to be fully effective in operation. The construction material installation method suitable for a robot which was developed in this paper is shown in Fig. 15. Each process can be outlined as follows:

1) First, construction materials piled on the ground are fixed to a robot with an adsorption device. The type of loading for materials carried from the ground is determined by the most efficient adsorption posture within the operation range of a manipulator.

2) An operator rapidly moves the robot to an installation site through a wireless controller . Here, a mobile platform whose velocity can be controlled by the input of a control sig nal is principally used. The posture of construction materials is adjusted by the motion of a manipulator if necessary.

3) Construction materials carried to the vicinity of an installation position are installed thr ough interaction with materials already installed by an operator. That is, compliance oc curs upon contact, so that press pits for materials and systems are completed safely.

4) After the operation is completed, the robot is returned to the site of construction materi als loading through a wireless controller for the next operation.

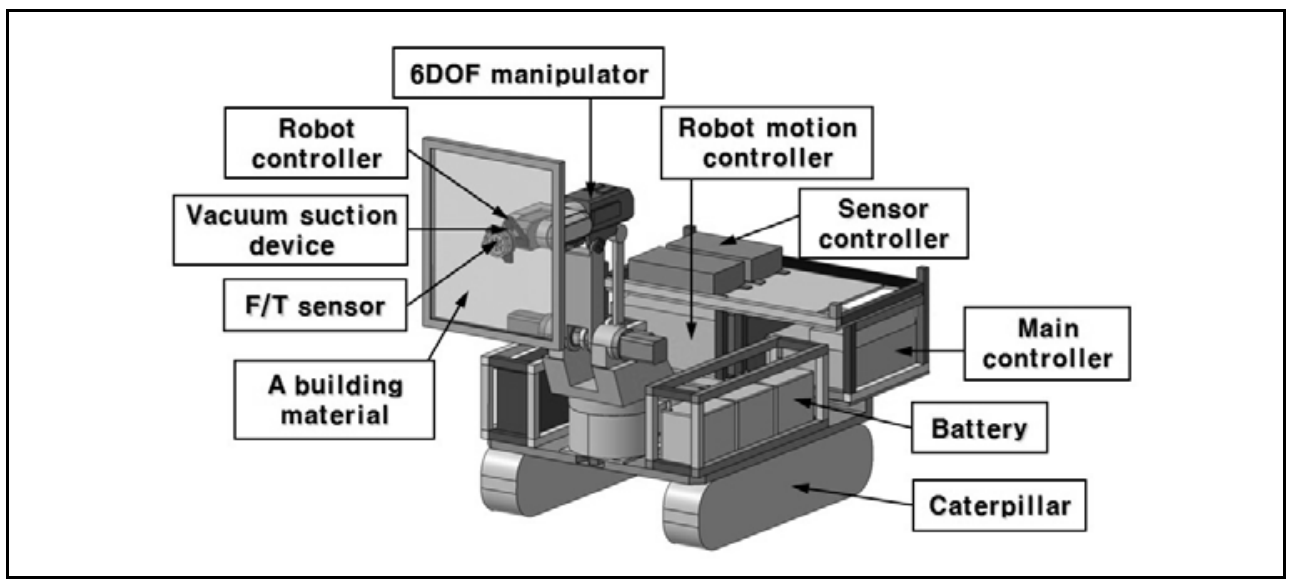

Fig. 14. The prototype of a MFR for handling building materials 


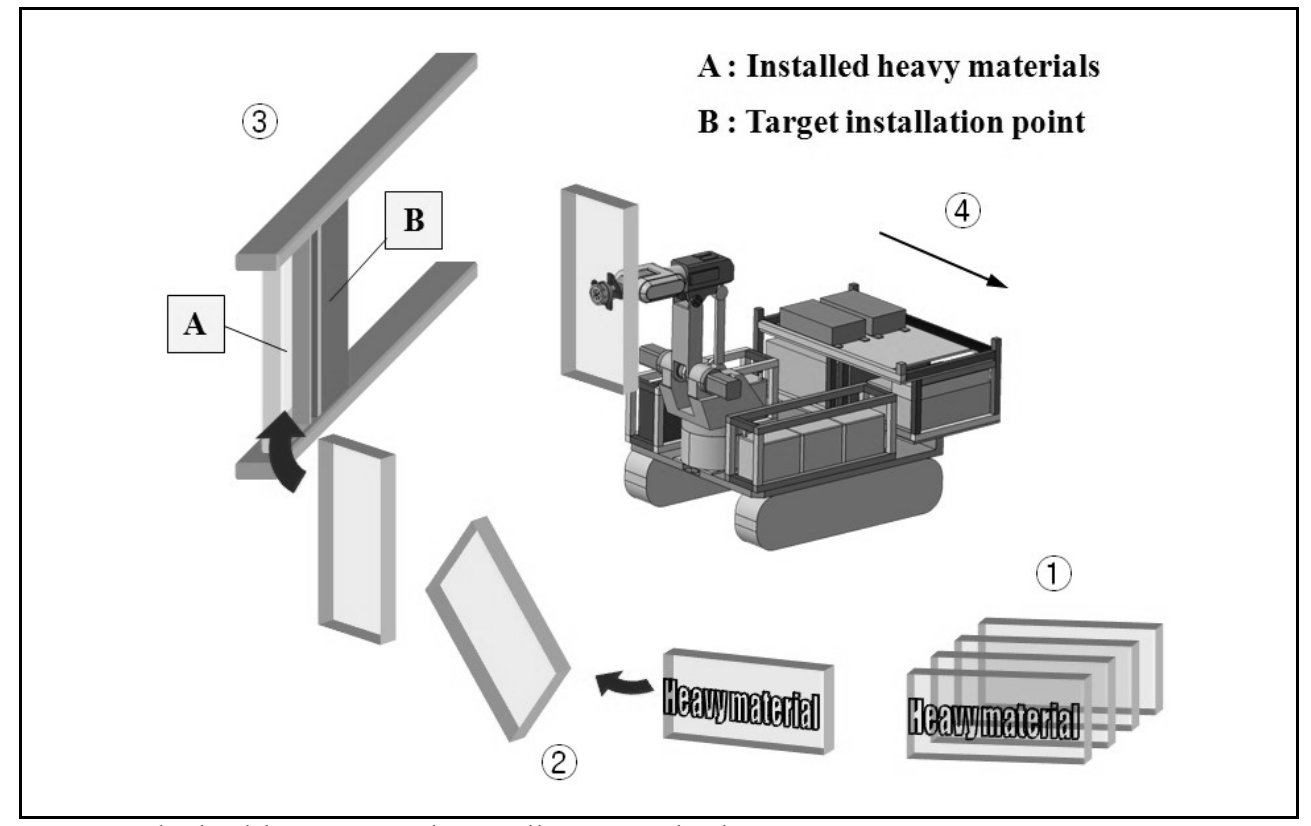

Fig. 15. The building materials installation method

A simulation for handling building materials is implemented to evaluate the performance of the prototype of MFR for construction works. The test is implemented indoors with an operation environment similar to that of an actual construction site. An experimental system to implement press pits after inserting building materials into the correct position was designed as in Fig. 16.

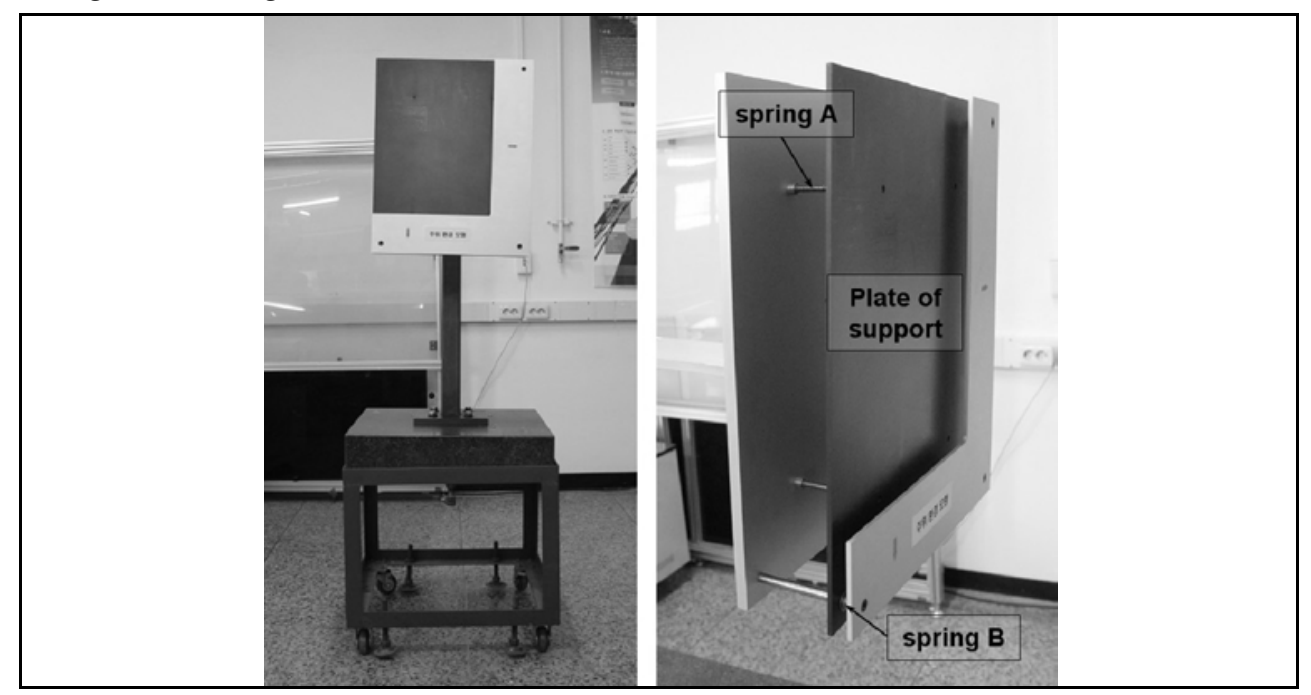

Fig. 16. An experimental system 
Inserting building materials between the supporting board and the L-board is substituted for actual installation operation. As the gap is narrower than the thickness of building materials, they are moved horizontally and vertically with the supporting board connected

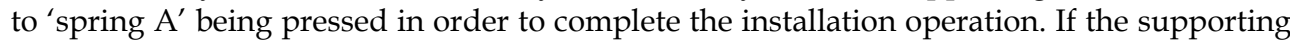
board is pressed, it means that compliance occurred; if the length of compression exceeds a certain range, the result is contact force which causes the robot to move in the opposite direction. In this experiment, building materials were limited to $60 \mathrm{~N}$, considering the specifications of the manipulator, and manufactured into models of curtain wall or panel.

Fig. 17 shows a simulation for handling building materials through an experimental system. Once building materials are completely fixed to a robot through a vacuum suction device at a loading site, the robot is moved relatively rapidly to the vicinity of the installation position through a wireless controller. Precise positioning is performed by human-robot cooperative control. In handling building materials, an operator is encouraged to collect information on the operation in real time in order to cope with changing environments. Here, the speed or efficiency of operation is proportional to an operator's workmanship.

Fig. 18 shows the result of a mock-up test of a building material handling work using an experimental system. A comparison was made between the contact force $\left(F_{e}\right)$ with environments and an operator's force $\left(F_{h}\right)$, measured by sensors during the handling of building materials. $F_{h}$ and $F_{e}$ refer to the mean value of forces measured in the $x, y$, and $z$ directions by a force/torque sensor during operation time $T_{h}$ and $T_{e}$, respectively, as shown in the following (10).

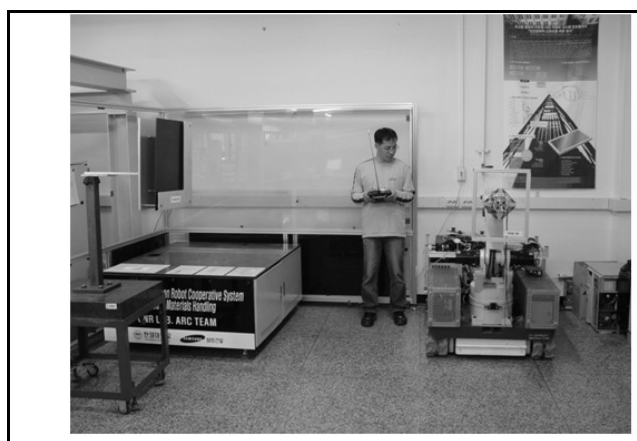

(a) Adsorption of a building material

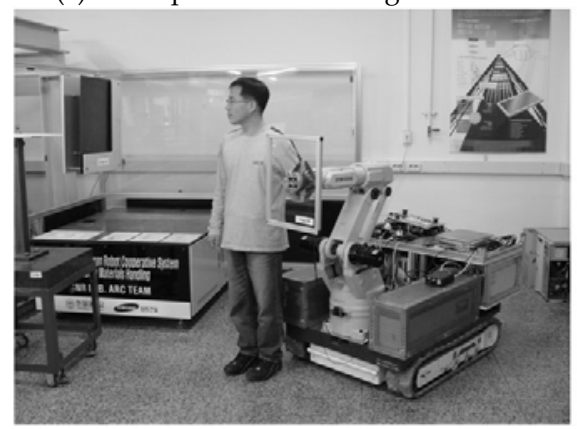

(c) Positioning through human-robot cooperation

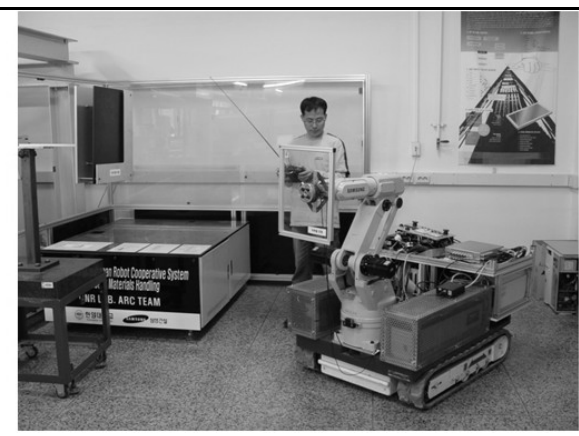

(b) Transportation through a wireless controller

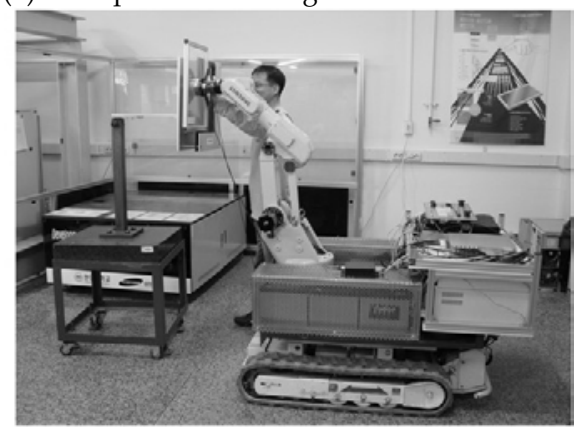

(d) Installing (coupling) of a building material

Fig. 17. An experimental system 


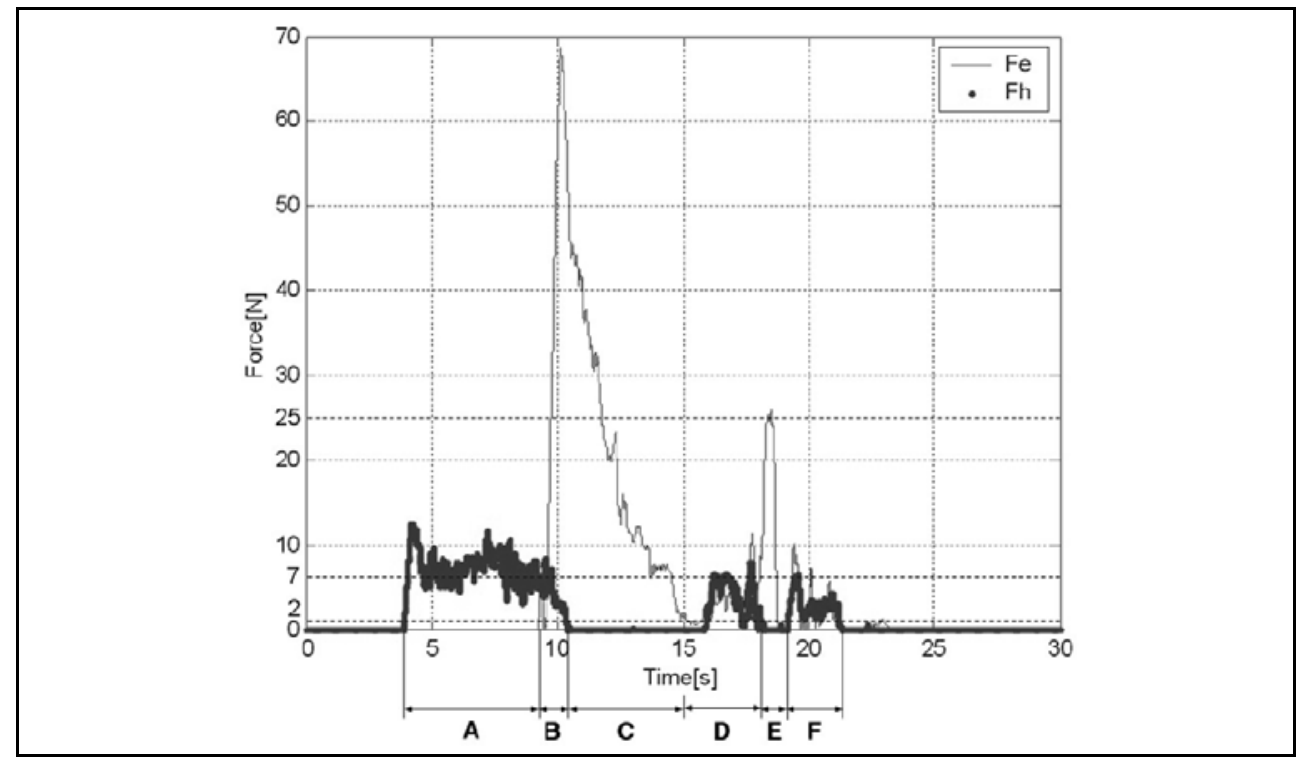

Fig. 18. $F_{e}$ and $F_{h}$ in simulation

$$
\begin{aligned}
& F_{h}=\int_{0}^{T_{h}} \frac{\sqrt{F_{h x}{ }^{2}+F_{h y}{ }^{2}+F_{h z}{ }^{2}}}{T_{h}} d t \\
& F_{e}=\int_{0}^{T_{e}} \frac{\sqrt{F_{e x}{ }^{2}+F_{e y}{ }^{2}+F_{e z}{ }^{2}}}{T_{e}} d t
\end{aligned}
$$

Each section can be described as follows:

1) Section A - A building material is carried to an installation position by the operators' fo rce $\left(F_{h}\right)$. As seen in the graph, about $50 \mathrm{~N}$ of building materials are carried by about 70 $\mathrm{N}$ of external force supplied by an operator. The force augmentation ratio $(a)$ is about 7 , which is necessary to access the supporting board of the experimental system.

2) Section B - Contact with the environment (experimental system) begins to occur, genera ting a maximum of $70 \mathrm{~N}$ of contact force $\left(F_{e}\right)$. Even at the moment of contact, the operat or's force is maintained to press the supporting board of the experimental system.

3) Section C - Not the operator's force but rather his or her torque is transmitted to improv e posture. About $2 \mathrm{~N}$ of compliance force is generated by the correlation between the ex ternal force provided and the impedance parameters of the experimental system. This value is used to press a spring connected to a supporting board into a position with a $\mathrm{c}$ ertain value.

4) Section D - A building material is carried horizontally to be inserted between the supp orting board and the L-board.

5) Section $\mathrm{E}$ - A building material is inserted; about $7 \mathrm{~N}$ of external force is provided by a $\mathrm{n}$ operator to make press pits, generating about $25 \mathrm{~N}$ of contact force.

6) Section F - Inserted horizontally, a building material is then inserted vertically. 
A total of about 17 seconds is spent on the test, with an average $7 \mathrm{~N}$ or less required of an operator.

\section{Conclusions and future works}

The prototype of MFR for handling building materials presented in this study combines a manipulator and a mobile platform standardized in modular form to compose its basic system. Also, the hardware and software necessary for each area of application were composed of additional modules and combined with the robot's basic system. The suggested MFR can execute particular operations in various areas such as construction, national defense and rescue by changing these additional modules. One of the advantages of the proposed MFR can be handled building materials through human-robot cooperation. For this cooperation, the robot controller (HRI device) and end-effector (vacuum suction device) are combined in the basic system. Also, human-robot cooperative control is done through target dynamics modeling of human, robot, environment and control of impedance and external force inputted from the power/torque sensor attached to the additional module. In addition, a wireless control and emergency control function were added through other extra equipment.

Applying the suggested MFR to construction works can be used as one of solutions to the problem of unbalanced supply of manpower, a problem raised in construction industry. Also, construction safety will be assured because when a construction material is implemented by press fit with a material already installed, compliance occurs within the elastic range of the material and it is installed without damaging either object.

The expected results applying to advantages and disadvantages of both existing curtain wall installation robot (ASCI) and MFR are compared with and analyzed in Table 4. As seen from the table, the proposed robot will be expected that it will be safer and more efficient than the existing one.

\begin{tabular}{|c|c|c|}
\hline Control mode & ASCI & MFR \\
\hline $\begin{array}{c}\text { Number of } \\
\text { workers }\end{array}$ & 2 & $\begin{array}{c}\text { Wire/Wireless/Human-robot } \\
\text { cooperation }\end{array}$ \\
\hline Working condition & Receive limited accurate information & Install materials intuitively \\
\hline Compatibility & Be restricted in specific work & $\begin{array}{c}\text { Be compatible in various work } \\
\text { through a change of a basic system } \\
\text { and additional modules }\end{array}$ \\
\hline Safety & $\begin{array}{c}\text { Damage to construction materials } \\
\text { and robot system by malfunction }\end{array}$ & $\begin{array}{c}\text { Protection construction materials } \\
\text { and system through force reflection }\end{array}$ \\
\hline
\end{tabular}

Table 4. Comparison and analysis of the ASCI and MFR in a construction site

A manipulator and a mobile platform, the basic system of the MFR, are combined to suit various working conditions and construction materials as module type. Therefore it is possible to install a variety of construction materials in various construction sites. Actual 
size of MFR for construction works is developing through the experiment result executed in our laboratory.

To apply a MFR at real construction sites, we must execute additional work required for application. Firstly, according to analysis of job definition and working condition, it is deduced that the conceptual design of a construction robot for installing bulk building materials. Secondly, practical arts (including robotized construction process) for applying to real construction sites should be proposed. Finally, after field test at a real construction site, productivity and safety of the developed system are compared with the existing construction equipment.

In next study, we will apply a MFR to a real construction site to install bulk glass ceiling that is installed $15 \mathrm{~m}$ above the ground. Also, in realizing the potential of the suggested MFR, additional modules which consider the abilities and specifications required by national defense and rescue operations will be developed in the future.

\section{Acknowledgement}

This work was supported by the Korea Research Foundation Grant funded by the Korean Government [KRF-2008-357-D00010].

\section{References}

Albus, James S. (1986). Trip Report: Japanese Progress in Robotics for Construction, Rototics Magazine, (Spring 1986)

Bernold, L.E. (1987). Automation and robotics in construction: A challenge and change for an industry in transition. International Journal of Project Management: The Journal of the International Project Management Association, Vol. 5, No. 3, page numbers (155160), ISSN 0263-7863

Choi, H.S., Han, C.S., Lee, K.Y. \& Lee, S.H. (2005). Development of hybrid robot for construction works with pneumatic actuator. Automation in Construction, Vol. 14, No. 4, (November 2004) page numbers (452-459), ISSN 0926-5805

Cusack, M. (1994). Automation and robotics the interdependence of design and construction systems. Industrial Robot, Vol. 21, No. 4, page numbers (10-14), ISSN 0143-991X

Fukuda, T., Fujisawa, Y., Arai, F., Muro, H., Hoshino, K., Miyazaki, K., Ohtsubo, K. \& Uehara, K. (1991). A New Robotic Manipulator in Construction Based on ManRobot Cooperation Work. Proceedings of the 8th International Symposium on Automation and Robotics in Construction, pp. 239-245, Stuttgart, Germany, June 1991, IAARC, Eindhoven

Fukuda, T., Fujisawa, Y., Kosuge, K., Arai, F., Muro, H., Hoshino, K., Miyazaki, K., Ohtsubo, K. \& Uehara, K. (1991). Manipulator for Man-Robot Cooperation. International Conference on Industrial Electronics, Control and Instrumentation, pp. 996-1001, Kobe, Japan, October 1991, IEEE, CA

Gambao, E., Balaguer, C. \& Gebhart, F. (2000). Robot assembly system for computerintegrated construction. Automation in Construction, Vol. 9, No. 5-6, (June 2000) page numbers (479-487), ISSN 0926-5805 
Han, H. (2005). Automated construction technologies: analyses and future development strategies, Master's thesis of science in architecture studies at the Massachusetts Institute of Technology, MA

Hogan, N. (1985). Impedance control: an approach to manipulation, Part I-III. ASME Journal of Dynamic Systems, Measurements and Control. Vol. 107, No. 3, (September 1985) page numbers (1-24), ISSN 0022-0434

Hollingum, J. (1999). Robots in agriculture. The Industrial Robot, Vol. 26, No. 6, (1999) page numbers (438-445), ISSN 0143-991X

Isao, S., Hidetoshi, O., Nobuhiro, T. \& Hideo, T. (1996). Development of automated exterior curtain wall installation system. Proceedings of International Symposium on Automation and Robotics in Construction, pp. 915-924, Tokyo, Japan, June 1996, IAARC, Eindhoven

Kangari, R. (1991). Advanced robotics in civil engineering and construction. 91 ICAR. Fifth International Conference on Advanced Robotics, pp. 375-378, ISBN 0-7803-0078-5, Pisa, Italy, 19-22 Jun 1991, IEEE, CA

Kazerooni, H. (1989). Human/robot interaction via the transfer of power and information signals - part I \& II: Dynamics and control analysis. IEEE Proc. of IEEE International Conference on Robotics and Automation, pp. 1632-1647, AZ, USA, May 1989, IEEE, CA

Kazerooni, H. \& Mahoney, S.L. (1991). Dynamics and control of robotic systems worn by humans, ASME Journal of Dynamic Systems, Measurement and Control, Vol. 133, No. 3, (September 1991) page numbers (379-387), ISSN 0022-0434

Kochan, A. (2000). Robots for automating construction-An abundance of research. Industrial Robot, Vol. 27, No. 2, page numbers (111-113), ISSN 0143-991X

Kosuge K., Fujisawa, Y. \& Fukuda, T. (1993). Mechanical system control with man-machineenvironment interactions. Proc. of IEEE International Conference on Robotics and Automation, pp. 239-244, Atlanta, USA, May 1993, IEEE, CA

Lee, S.H. Adams, T.M. \& Ryoo B.Y. (1997). A fuzzy navigation system for mobile construction robot. Automation in Construction, Vol. 6, No. 2, (May 1997) page numbers (97-107), ISSN 0926-5805

Lee, S.Y., Lee, K.Y, Lee, S.H, Kim, J.W. \& Han, C.S. (2007). Human-Robot Cooperation Control for Installing Heavy Construction Materials. Autonomous Robots, Vol. 22, No. 3, (April 2007) page numbers (305-319), ISSN 0929-5593

LeMaster, E.A. \& Rock, S.M. (2003). A local-area GPS pseudolitebased navigation system for mars rovers. Autonomous Robots, Vol. 14, No. 2-3, (March 2003) page numbers (209224), ISSN 0929-5593

Miller, J.S. (1968). The Myotron - A Servo-controlled exoskeleton for the measurement of muscular kinetics. Cornell Aeronautical Laboratory Report VO-2401-E-1

Masatoshi, H., Yukio, H., Hisashi, M., Kinya, T., Sigeyuki, K., Kohtarou, M., Tomoyuki, T. \& Takumi, O. (1996). Development of interior finishing unit assembly system with robot: WASCOR IV research project report. Automation in Construction, Vol. 5, No. 1, (1996) page numbers (31-38), ISSN 0926-5805

Mosher, R.S. (1967). Handyman to Hardiman. Automotive Engineering Congress. SME670088

Poppy, W. (1994). Driving force and status of automation and robotics in construction in Europe. Automation in Construction, Vol. 2, No. 4, page numbers (281-289), ISSN 0926-5805 
Roozbeh K. (1985). Advanced Robotics in Civil Engineering and Construction. Proc. of IEEE International Conference on Robotics and Automation, pp. 375-378, Tokyo, Japan, September 1985, IEEE, CA

Santos, P.G., Estremera, J., Jimenez, M.A., Garcia, E. \& Armada, M. (2003). Manipulators helps out with plaster panels in construction. The Industrial Robot, Vol. 30, No. 6, (2003) page numbers (508-514), ISSN 0143-991X

Skibniewski, M.J. (1988). Robotics in civil engineering, Van Nostrand-Reinhold, ISBN 0442319258, New York

Skibniewski, M.J. \& Wooldridge, S.C. (1992). Robotic materials handling for automated building construction technology. Automation in Construction, Vol. 1, No. 3, (1992) page numbers (251-266), ISSN 0926-5805

Warszawski, A. (1985). Economic implications of robotics in building. Building and Environment, Vol. 20, No. 2, page numbers (73 81), ISSN 0360-1323

Wen, X., Romano, V.F. \& Rovetta, A. (1991). Remote control and robotics in construction engineering. 91 ICAR. Fifth International Conference on Advanced Robotics, ISBN 0-7803-0078-5, Pisa, Italy, 19-22 Jun 1991, IEEE, CA

Whitcomb, L.L. (2000). Underwater robotics: Out of the research laboratory and into the field. Proceedings of IEEE International Conference on Robotics and Automation, pp. 709716, ISBN 0-7803-5886-4, San Francisco, USA, April 2000, IEEE, CA

Wong, B. \& Spetsakis, M. (2000). Scene reconstruction and robot navigation using dynamic fields. Autonomous Robots, Vol. 8, No. 1, (January 2000) page numbers (71-86), ISSN 0929-5593 


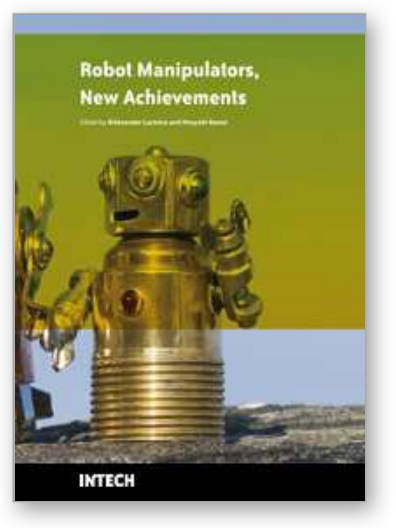

\author{
Robot Manipulators New Achievements \\ Edited by Aleksandar Lazinica and Hiroyuki Kawai
}

ISBN 978-953-307-090-2

Hard cover, 718 pages

Publisher InTech

Published online 01, April, 2010

Published in print edition April, 2010

Robot manipulators are developing more in the direction of industrial robots than of human workers. Recently, the applications of robot manipulators are spreading their focus, for example Da Vinci as a medical robot, ASIMO as a humanoid robot and so on. There are many research topics within the field of robot manipulators, e.g. motion planning, cooperation with a human, and fusion with external sensors like vision, haptic and force, etc. Moreover, these include both technical problems in the industry and theoretical problems in the academic fields. This book is a collection of papers presenting the latest research issues from around the world.

\title{
How to reference
}

In order to correctly reference this scholarly work, feel free to copy and paste the following:

Seungyeol Lee (2010). MFR (Multi-purpose Field Robot) Based on Human-Robot Cooperative Manipulation for Handling Building Materials, Robot Manipulators New Achievements, Aleksandar Lazinica and Hiroyuki Kawai (Ed.), ISBN: 978-953-307-090-2, InTech, Available from: http://www.intechopen.com/books/robotmanipulators-new-achievements/mfr-multi-purpose-field-robot-based-on-human-robot-cooperativemanipulation-for-handling-building-ma

\section{INTECH}

open science | open minds

\section{InTech Europe}

University Campus STeP Ri

Slavka Krautzeka 83/A

51000 Rijeka, Croatia

Phone: +385 (51) 770447

Fax: +385 (51) 686166

www.intechopen.com

\section{InTech China}

Unit 405, Office Block, Hotel Equatorial Shanghai

No.65, Yan An Road (West), Shanghai, 200040, China 中国上海市延安西路65号上海国际贵都大饭店办公楼 405 单元

Phone: +86-21-62489820

Fax: $+86-21-62489821$ 
(C) 2010 The Author(s). Licensee IntechOpen. This chapter is distributed under the terms of the Creative Commons Attribution-NonCommercialShareAlike-3.0 License, which permits use, distribution and reproduction for non-commercial purposes, provided the original is properly cited and derivative works building on this content are distributed under the same license. 